\title{
VICENTE GERBASI, MODERNO. NUESTRO ÚNICO PADRE ES EL MORIR
}

POR

Patricia Guzmán

\section{Vicente Gerbasi, NUESTRO MODERNo}

Vicente Gerbasi (Canoabo 1913/Caracas 1992) abrió los ojos para dormir (en brazos de una psique automatizada) y cerró los ojos para despertar (del sueño creador) un día (y todos los días) Viernes. Sucedió en medio de un Bosque doliente (editado por el sello Viernes en 1940, cuando ya había publicado su primer libro de poemas, Vigilia del náufrago, 1937),"bosque de sueños, jardín viejo lleno de sombras, bosque umbroso de sinfonías, donde se esconde el Ser en los tiempos de tristeza". Sucedió cuando supo que Creación y símbolo (1942, también del sello Viernes) marchaban de la mano: quien crea ha entendido que el símbolo tiene un trasfondo hondo donde yacen imágenes maceradas, reconcentradas; emociones, "oscuridades audibles", lo inefable (aún por ser expresado).

Ese cuadernillo de ensayos expresa su deseo de aprehender la naturaleza de las palabras, de las imágenes, de los adjetivos metaforizantes, de los ritmos, de los silencios, sobre todo de los silencios (pura esencia de mundo, contención de mundo) con los que estaban hechos los poemas que tanto amaba y que tanta forma le daban a él y a sus versos. Él, tan moderno, que pudo entender - románticamente - la vida como una flor azul perdida en el fondo del corazón (Novalis). Él, tan moderno, que sufrió con Mallarmé ante la página en blanco. Él, tan moderno, que asumió el surrealismo como una aproximación entre poesía y vida; aunque a veces la última fuera "sacrificada" en virtud de la primera.

Sucede que Gerbasi, como la mayoría de los integrantes de Viernes, intenta hacerse de una trama analítica que le ayude a "resolver" (mirar de cerca; jamás encontrar salidas) la compleja problemática del quehacer poético. Y a sabiendas de que las arenas de la poesía venezolana son movedizas, capaces de absorber distintas mareas hasta filtrarlas y dejar guardada en sí, sedimentada, la sal que mejor nos viene, abrió un horizonte de expectativas amplio, plural.

\section{SE PUEDE SER TAN MODERNo CON PARÍS COMO CON CANOABO}

Si la sugerencia no basta, seamos directos junto a Ludovico Silva: Vicente Gerbasi, "poeta denso de memoria, de vida, de sabiduría formal, poeta de la modernidad". Poeta

\footnotetext{
1 J. Silva, La torre de los Angeles (Caracas: Monte Ávila, 1991) 37.
} 
que sabe tanto de artificio formal como del arte adivinatorio. Ello lo convierte en un filósofo de la realidad. Pone su cabeza de nube (así lo han visto los poetas amigos) contra el cielo para llenarse de pájaros y para que el cielo se llene de flores de cacao, para que el tigre y alguna constelación se miren y se espanten como frente a un espejo.

Porque Gerbasi no dejará nunca de ser Canoabo, su tierra natal, tierra psíquica; pero hará de Canoabo, siempre, un (el) universo. Desde allí inventará fantasmas. Lo real mismo, el "ser", el to hon parmenídico y platónico, se revela como una apariencia, esto es, como una fantasía, una aparición. Pero hay más. Si, según la dialéctica platónica, hay que llegar a un ser fijo y ultraterrestre para poder conocer, el poeta lo acompañará, pues el poeta no se queda flojo a la hora de ascender la escala del conocimiento.

Venimos de la noche, y hacia la noche vamos (Silva 40-41).

El poeta se ganó un puesto en la modernidad. Ni por su fuerza o virtud metafórica ni por su dominio del ritmo ni por su conciencia del espacio de la página ni por otras cualidades formales. Oyó como Baudelaire la lírica antigua, griega, latina, y le imprimió a las palabras un carácter ontológico. Heidegger, explica Silva, habla de diferencia ontológica cuando quiere distinguir entre poemas hechos de palabras y poemas Hechos de Palabras: puestas en su justo lugar (Silva 42).

Gerbasi ha dicho: "En poesía las palabras no poseen un valor justo, filológico, etimológico, sino que adquieren un valor múltiple, que escapa a la lógica corriente del lenguaje. La palabra cambia de valor con su relación" (Gerbasi en Silva 43).

Mallarmé llamó a ese valor, prismático; Baudelaire, evocatorio (Sivla 43). Vicente Gerbasi se aferró a tal dinámica urgido de no salir nunca del reino mántico (evocar antes que significar).

Termina Silva por inscribir el nombre de Gerbasi entre los modernos al comentar: "Gerbasi nos habla de pequeños pueblos, de pequeñas cosas, pero les da un relieve estilístico de gran poder adivinatorio. Tiene la misma 'sorcellerie évocatoire' o brujería evocatoria de Baudelaire. Este nos describe y nos canta París; Gerbasi describe y canta a Canoabo, un pequeño pueblo del estado Carabobo, donde murió su padre, que era un inmigrante italiano. Se puede ser tan moderno con París como con Canoabo" (Silva 45).

Coronar la PALABRA CON EL SímbOLO

Albert Béguin lo conmueve y lo reasegura al permitirle pensarse como a un microcosmos constituido a la manera del Universo; un microcosmos que se erige como una imagen del Cosmos. Basta con abrir la puerta de nuestro inconsciente: allí, entre tanta oscuridad, aparece Dios; allí ocurre cualquier epifanía. Que podemos llamar magia.

Allí, hasta esa puerta, sólo se llega en sueños. La vigilia, el duermevela, son estados alquímicos: lo vivido y lo olvidado han de convertirse en sangre que nutra los versos que estamos llamados a escribir.

Tendrá el poeta que escribir de noche, en la oscuridad y el silencio que desnudan al místico y al poeta. Sólo somos pasajeros de la noche - "venimos de la noche y hacia la noche vamos"- ha dicho Gerbasi reiteradamente. 
"En su proximidad al misterio, en su hondo espejo del cosmos, en su insondable silencio estrellado, en su invitación al infinito, se hacen posibles el ángel y el demonio, la serenidad y el caos". ${ }^{2}$

Inconsciente, sueño, magia, noche, poesía .... todo ello lo reconoció Gerbasi en los románticos. Leería a Béguin, junto a sus compañeros de Viernes, tempranamente, al publicarse L'Âme romantique et le rêve: Essai sur le Romantisme allemand et la poésie française (1939). Lo reproducen en la Revista Nacional de Cultura, 18 ("Los románticos y el inconsciente", Caracas, mayo de 1940). Hablan del "gran libro".

Para insistir en la inclinación de Gerbasi y de Viernes por los románticos, cabe citar nuevamente a la Revista Nacional de Cultura, 19 (abril de 1940). Humberto Díaz Casanueva revisa junto a Heidegger las reflexiones de Hölderlin sobre la esencia de la poesía. El poeta chileno ya les había hecho leer sus traducciones de la obra de éste. Maurice Boersner, crítico alemán también residenciado en Caracas, les habló de Rilke (Revista Nacional de Cultura 14-15), lo que movió a los viernistas a publicar en su revista (1941) cuatro poemas (traducidos en Argentina) de ése que nos invita a merecer, a construir, nuestra propia muerte.

¿Otro hubiera sida el decurso del pensamiento poético venezolano de finales de los años treinta? Sin la presencia de Díaz Casanueva quizá sí. Del discípulo de Heidegger, del docente que vendría a asesorar, por petición de Mariano Picón Salas, en la creación del Instituto Pedagógico Nacional, no puede decirse menos que maestro. Su sólida formación y su fuerza de poeta dispuesto a oscurecerse para huir de los que él mismo llamó "la fácil canción inofensiva", le abrieron el mejor lugar entre los miembros de Viernes.

Cuando llegó a Venezuela traía consigo El aventurero de Saba (1926) y Vigilia por dentro (1931). En el país escribiría El blasfemo coronado (1940), libro de prosa poética que raptaría a Gerbasi. Tanto que le dedicó un concentrado ensayo en Creación y símbolo (los otros dos estarían dedicados a Luis Fernando Álvarez y a Otto De Sola; todos, compañeros de Viernes).

Interesa detenerse en la lectura de El blasfemo coronado que emprende Gerbasi dado que es altamente reveladora del ángulo desde el cual nuestro poeta mira, percibe, asimila la experiencia poética. Se nos revela no únicamente su acercamiento a Díaz Casanueva. Se hace patética frente a nosotros el ansia de Gerbasi ante el ser y su estar en el mundo: ineludiblemente inasible, como el fuego: "El fuego que nos devora está dentro de nosotros y sólo de cuando en cuando lo trasmitimos". ${ }^{3}$

A la luz de ese fuego, Gerbasi ve a Díaz Casanueva como un "sagrado sacerdote ... Este gran poeta del misterio del hombre se embriaga en la duda y se acerca tambaleante a lo desconocido. Los enigmas del ser tienden una red oscura a su redor" (Gerbasi, La rama 73).

¿Moriré de mi muerte? Yo nada sé, yo tiemblo apenas y uñas se me clavan buscando lugar.

\footnotetext{
${ }^{2}$ V. Gerbasi, "Mi padre el inmigrante", Obra poética (Caracas: Monte Ávila, 1980) 322.

${ }^{3}$ V. Gerbasi, La Rama del Relámpago (Caracas: Casa de Bello, 1984) 73.
} 
La pregunta del sacerdote es la misma pregunta de Rilke. La misma de Gerbasi: "¿Quién que viva penetrado en su existencia, en sus vivencias, no es asaltado por esta torturante pregunta rilkeana? Nada hay más cerca dentro de nosotros que la vida y la muerte. Queremos vivir una vida nuestra, donde nuestro yo alcance una radiante plenitud. Esto significa aspirar a nuestra propia muerte" (Gerbasi, La rama 74).

Líneas aparte, Gerbasi avanza en un solo párrafo consagrado a Díaz Casanueva, lo que terminaría por conformar su ars poética. El enigma del ser está escrito en la piel del cosmos. Hay que aprender a hablarle, a orarle, para alcanzar la redención. "Su aproximación a la realidad le hace brotar poemas duros, primitivos, ásperos, quemantes, de cierta extraña fuerza mágica. El amor poético con que Díaz Casanueva se acerca a las cosas, a los hechos, a las verdades visibles y a los misterios del hombre, se convierten en furia, en blasfemia, en peligro. En este estado de ira, de rebelión, de fuga libertaria, entra en una atmósfera cósmica. Es aquí cuando se revelan sus potencias irracionales que dan a su voz el timbre de la revelación. A través de sus palabras llega a nosotros, entre imprecaciones la suplicante y dura voz de los salmos" (Gerbasi, La rama 76)

Todo ello sólo puede decirse de una manera sugerente, desde el intersticio del lenguaje, haciéndonos de palabras que se asoman, que dejan medio cuerpo en lo negro y entregan medio cuerpo a la conciencia. Palabras simbólicas: una rosa puede clavársenos en los labios como una espada. La imaginación nos trae las cosas, las arranca del inframundo. (Así lo quisieron Verlaine, Rimbaud, Mallarmé .... Rubén Darío ....).

Aquí se abre el terreno, se parte en dos para indicarnos que Gerbasi, cuando lee a Díaz Casanueva y subraya su simbolismo, está mimetizado con el poeta chileno en su lectura del surrealismo.

.... El carácter "automático" de la imaginación surrealista no se concilia con mi afán de coaligar el fondo más tenebroso, irracional, incoherente y la lucidez más implacable junto con la emisión de sentido. Me convencen, naturalmente, las fuentes de lo insólito y el "azar objetivo". He querido trazar un camino que vaya de la metáfora a la imagen visionaria y luego al símbolo. Eluard dice: "ella muestra senos que matan insectos rojos ...."; es bello aunque un poco artificioso, lirismo de una percepción visual imaginada. John Ashbery dice: "El joven coloca una pajarera contra el mar azul/ hombres aparecen pero ellos viven en cajas/ hay choques comunicaciones en la playa". Aquí hay mayor emotividad, sugestión, intensidad culminante, belleza perturbadora. Definitivamente, mi poesía ha seguido un curso simbólico muy agudo, luego, el ámbito visionario que logro crear (esto me ha sido reconocido) y el verbo que en su descoyuntamiento produce significación ... El símbolo en comparación con la imagen, tiene más trasfondo, cualidad imaginativa, emoción, magia verbal. Algo, lo inefable, se revela mejor a través del símbolo que en la expresión directa o en el símil. ${ }^{4}$

Aclara Díaz Casanueva que la imaginación simbólica no está divorciada de lo real corriente. Allí, en lo real corriente, en el paisaje por ejemplo, se revela el misterio espontáneamente. "El poeta — vuelve Gerbasi para referirse no únicamente a Díaz Casanueva - posee la facultad de penetrar en la esencia de las cosas. La naturaleza le

${ }^{4}$ B. Espinoza, "Entrevista a Humberto Díaz Casanueva", LAR (Revista de Literatura) (Chile, mayo, 1986) 6. 
muestra su misterio y ese misterio es percibido y expresado por el poeta en símbolos, mucho más cuando esos misterios poseen una profunda relación con el misterio subjetivo del poeta" (Gerbasi, La rama 77).

El misterio subjetivo de Díaz Casanueva está hecho de graves vivencias. De experiencias están hechos sus versos o vesículos, apunta Gerbasi para pasar a citar una ver más a Rilke: "Los versos no son, como algunos creen, sentimientos (estos se tienen demasiado pronto), son experiencias. Para escribir un solo verso es preciso haber visto muchas ciudades, hombres y cosas, es preciso sentir cómo vuelan los pájaros y saber el movimiento que hacen las pequeñas flores abriéndose en la mañana" (Gerbasi, La rama 80).

Pero, no puede Vicente Gerbasi enfrentar la poesía —en ningún caso- sin pensarla en un contexto americano. Puede él estrecharle la mano a Valéry y a Rimbaud, besar en la frente a Baudelaire, citar de corazón a Rilke, pero no olvida que su sino, incluso su sino creativo, está ligado a América y a lo que ella connota: ella misma es misterio, bruma, aspereza y maravilla.

Humberto Díaz Casanueva en El blasfemo coronado es uno de los poetas más americanos de los actuales momentos. Pero lo americano en él no es decorativo, sino lo profundo del misterio americano. América todavía es un misterio y como misterio ha de expresarse. Para encontrar a América es preciso buscarla en su caos, que va desde la vida cosmopolita de sus grandes puertos y ciudades, pasa por las vastas comarcas que nosotros los iberoamericanos llamamos interior, con sus llanos, montañas y abruptas regiones despobladas, y llega hasta el hinterland, donde florecen selvas alucinantes y plenas de peligro, cruzadas por anchos ríos oscuros y convulsos, en cuyas márgenes habita el indio en su primitiva actitud de acechanza (Gerbasi, La rama 81 ).

UNA EXPRESIÓN (PROPIA) QUE RESPONDA A LO UNIVERSAL

Vicente Gerbasi resolvió ambas tareas: develar el misterio americano y, he allí la segunda misión, de mayor dificultad, expresarlo desde su particularísima experiencia; expresarlo desde aquí pero con la voz que nace en sus entrañas, proyectada hacia afuera.

Así hizo su obra, bajo tales señas de identidad, y así, incuestionablemente, hizo definitivamente moderna la poesía venezolana.

Por ello fue el primero en reconocer y en cuestionar nuestra herencia. Se detuvo (en otro conjunto de ensayos denominados La rama del relámpago $o^{5}$ ) frente a Andrés Bello (frente a su silva a "La agricultura de la zona tórrida") para identificarlo como "el primer latinoamericano que nombra con el verbo de la poesía los elementos que constituyen nuestra nostalgia y conforman el alma de nuestro pueblo. Andrés Bello es el que nombra por primera vez lo venezolano en la poesía" (Gerbasi, La rama 94).

Advierte Gerbasi que Bello nombra lo venezolano haciéndose eco de un lenguaje clásico, heredado de Europa y nunca matizado con su visión particular. Vio alegría donde

\footnotetext{
${ }^{5}$ Conjunto de notas publicadas en El Nacional, recogidas junto a los ensayos titulados "Creación y símbolo", La Rama del relámpago (Caracas: Casa de Bello, 1984). Destaca allí su posición "revisionista" de la evolución de la poesía venezolana.
} 
hay desolación, vio belleza apacible donde hay sólo tormento tropical. "Bello nombró en poesía lo venezolano con el lenguaje de su tiempo, con la sensibilidad de su época. Nosotros estamos en la obligación de tener presente a Bello como un buen ejemplo, pero no podemos imitarlo, porque nuestro tiempo no nos lo permite, porque la evolución de las concepciones estilísticas nos obliga a someternos a ello" (Gerbasi, La rama 95).

Inicia Bello nuestra tradición poética porque vio y dijo nuestra naturaleza. Así lo reconoce Gerbasi pero se le impone el desasosiego ante la necesidad de encontar un lenguaje capaz de expresar in essentia a América.

América, y especialmente sus regiones equinocciales, tiene necesidad, para ser expresada, si no de un lenguaje poético, por lo menos de un lenguaje profundamente dinámico, tenso, lúcido, que revele las potencias, los enigmas y las furias de nuestra ardiente y áspera geografia, donde el hombre, como por un mimetismo de los sentidos, parece estar siempre confundido en ella (Gerbasi, La rama 95).

Se adelantó Gerbasi a inquirir a los poetas de América. Urgía religar lenguaje y naturaleza, hacerlos resonar. Los invitó a "conformar su lenguaje a esa naturaleza que los rodea. Su poesía ha de ser una poesía prometéica como es prometéico el hombre que es devorado lentamente por esta tierra" (Gerbasi, La rama 96).

Reclamó Gerbasi mucho a nuestra poesía, a nuestro arte en general, no tener un carácter nacional. Pensaba en un César Vallejo en Perú; en Neruda, en Rosamel del Valle y el mismo Díaz Casanueva, en Chile. Y cuando decía nacional pensaba en el trópico, en un trópico propicio a los demoníaco, a la "violencia cósmica".

Volvía con obstinación a Rilke, retomaba su lección sobre la poesía con experiencia, y concluía:

Basta haber vivido algún tiempo en alguna de nuestras pródigas comarcas, haber recorrido sus días en que los sonidos se petrifican y brillan en el sol de las cigarras; haberse recogido con los animales bajo las oscuras lluvias vegetales; haber sentido la noche como un viento arenoso, como relucientes garras negras, como insectos, como luciérnagas, como una leyenda de familiares fantasmas; haber sentido la noche como el olor del café y del cacao, como la fosforescencia de los espacios en que deambula el tirano Aguirre, en que nacen voces de los árboles, de las rocas, de las tristes viviendas y de las más profundad soledad de la sombra, para darnos cuenta de que estamos en posesión de una insospechada experiencia (Gerbasi, La rama 100$)$.

Experiencia que nuestros creadores deben expresar. No interpretando lo nacional puesto que ello sólo lleva a lo "elementalmente nativista, criollista, decorativo, descriptivo y muchas veces demagógico" (Gerbasi, La rama 101).

La médula del cuerpo de la poesía moderna había sido tocada por Vicente Gerbasi. "Bastante se ha dicho que en arte se debe partir de lo local para llegar a lo universal. Pero creo que el medio para lograrlo es aprovechando las experiencias, las vivencias que nos ofrece el mundo mediante una expresión que responda a lo universal ... Lo importante es saber expresar lo local y a la vez ser un hombre de su propio tiempo" (Gerbasi, La rama 101). 


\section{Gerbasi el VIDENTE}

La última noche supo que era huérfano. Y la noche derrumbó los árboles para que no olvidara que su padre nunca nació. O nunca le besó por dentro los ojos. O nunca le enseñó a mirar a lo Abierto, a mirar como los animales: profundamente, perdidamente.

Entonces decidió invertir las sombras del camino. El morir ya no le seguiría los pasos. Dios dejaría de estar ante sí. Ahora lleva la muerte en las manos y a Dios sobre la espalda. Y mientras se desplaza, anda eternamente, así como fluyen las fuentes, así como quería Rilke.

Su pena primordial - la orfandad que nos constituye: estamos íngrimos, no conocemos el nombre de nuestro progenitor- ha sido purgada. Del otro lado no se necesita tener padre. Se sabe sin apellido y no le duele. Abre los brazos para que los pájaros aligeren su carga: la tierra que le quedó entre las uñas cuando fue enterrado. Abre los brazos y camina hacia adelante escuchando dentro de si a la quinquina: ella lo llevará hasta el Paraíso y él abrazará a los oriundos del lugar; todos nacidos en Canoabo.

Allá nada le parecerá nuevo. Nada lo hará llorar. El ya conoce el Absoluto. Hace muchos años descubrió que el lugar pleno, el mundo pleno no está "en otra parte", ni "allá lejos", sino "aquí". Pero ese aquí resplandece sólo gracias a la poesía. Gracias a los vocablos que han vulnerado las leyes del sentido, que han sido arrancados al frío y a la inercia. Y es que lo que importa - como lo subraya Starobinsky al pensar en la obra de Bonnefoy - no es la multiplicidad de los objetos denotados, sino la calidad de la relación que los pone en presencia recíproca.

Hay que abrir las palabras, esclarecerlas. Hay que herirlas, hacerlas chillar. De manera que se llenen de otro aire y de otra vida. Reanimadas serán capaces de ponernos de cara a lo inmenso-inédito. Reanimadas serán capaces de hacernos reconocer ese invisibleadelante.

Él lo hizo. Convirtió el acto de habla no en simulacro sino en epifanía: en anunciación. En gesto de adoración al mundo. Y acaso también instauró al Ser. Le dio morada siguiendo la premisa de Heidegger.

Ser y mundo le pertenecieron en su más genuina expresión porque tenía la boca limpia, llena de palabras puras; porque tenía el ojo limpio, como lo reclama la Biblia: "La lámpara del cuerpo es el ojo; así que si tu ojo es bueno, todo tu cuerpo estará lleno de luz. Pero si tu ojo es maligno, todo tu cuerpo estará en tinieblas".

Con ese ojo lleno de agua bendita avizoró un bosque de símbolos; la naturaleza toda esplendor.

HoMBre PAISAJE: AQUí REINA LA VIOLENCIA CóSMICA

El hombre despliega espacio. El hombre conquista un lugar, lo transforma en espacio vivido. Y, las más de las veces, trata de inaugurar ese lugar en la naturaleza, en el paisaje, al rozar el bosque.

El hombre sintió desde siempre que en la naturaleza todo le esperaba y, plantea Rilke, "donde él llegaba, todo se retiraba y le hacia sitio". ${ }^{6}$ El hombre, a menudo, más que

\footnotetext{
${ }^{6}$ R. M. Rilke, Teoría poética (Madrid: Júcar, 1987) 206.
} 
designar el paisaje, ha querido designarse él mismo dentro del paisaje. El hombre intuye, y el poeta se atreve a aseverar, que procedemos del paisaje, que existe un vínculo primero.

No obstante, ella, la naturaleza, es más grande y más duradera. Estamos expulsados, echados de sus entrañas. He allí el sentimiento trágico que signa al poeta, he allí la dolorosa revelación: el hombre está puesto entre las cosas como una cosa, infinitamente solo.

Por ello la auténtica tarea que puede restablecer nuestra comunión con la naturaleza es la que le propuso Baudelaire a Vicente Gerbasi: ver en ella un inmenso depósito de analogías, un almacén de imágenes y signos que deben ser traducidos por la imaginación. Novalis agrega que todo lo visible descansa sobre un fondo invisible; lo que se oye, sobre un fondo que no puede oirse; lo tangible, sobre un fondo impalpable, porque "lo que importa en las percepciones es que puedan, en ciertos casos, llevarnos hasta lo oculto", hasta lo Absoluto.

El alma del campesino educado en Florencia - como lo llamaba su esposa, Consueloencontrará su patria en la naturaleza, y la naturaleza revelará sus enigmas a la luz del espíritu de éste, siempre que la poesía le preste sus palabras. "La poesía, que precisamente es la que más sabe decir del alma cuando expresa paisajes" (Rilke 208). La poesía, que a veces nos presenta al hombre como procedente del paisaje, $y$, otras, al paisaje brotando del hombre.

La experiencia se radicaliza aún más en el trópico, donde la naturaleza se impone de manera más definitiva y con un carácter más amenazante. El trópico nos sensibiliza, nos inclina hacia lo demoníaco, hacia el peligro, hacia el encantamiento.

Aquí el veneno persigue al hombre bajo el verde húmedo del helecho, en las grietas rojas de la tierra o en las grandes hojas de las espesas arboledas .... Aquí las fuerzas de la naturaleza están siempre cerca de la cólera. Aquí reina la violencia cósmica. América produce angustia, sobresalto, tristeza (Gerbasi, La rama 100).

Al decir del poeta, quien aproveche esa fuerza, quien penetre en la esencia misteriosa de nuestras tierras y la exprese con voz muy propia, con la huella de sus angustias, con el aura de sus sueños, pero resonando en una expresión que responda a lo universal, estará escribiendo la gran poesía de América para todos, para el mundo. Y estará propiciando una correspondencia entre su lugar, el allí desde donde se dice y se realiza, y el Absoluto. Ese lugar lo sostendrá para soportar el peso del misterio y la palabra poética no sólo nos revelará el mundo, la entenderemos como una rebelión contra el misterio.

Gerbasi encabeza ese reducido grupo de poetas latinoamericanos que han escrito una poesía netamente afincada en el paisaje del continente, nutrida del fuego, la garza, las anchurosas soledades, desde su propio tiempo de creadores que deben responder a los patrones estéticos universales que dignifican el acto de escribir poesía. Lejos de todo naturalismo, chauvinismo, criollismo, enfrentan a.la naturaleza buscando en un fruto no sólo su nombre - ¿de qué sirve decir, sin más, guayaba? - sino la promesa de un mundo. Lejos de todo afán reduccionista, intentan entregarnos el todo antes que las partes.

\footnotetext{
${ }^{7}$ M. Raymond, De Baudelaire al Surrealismo (México: Fondo de Cultura Económica, 1968) 17.
} 
Gerbasi, como todo artista de hoy, recibe del paisaje el lenguaje para sus confesiones; se sirve de la naturaleza como de un diccionario. Y aprende de Lezama Lima que la imagen es naturaleza sustituida.

Para Gerbasi el paisaje es su razón de ser.

Existo por razones de espacio.

Me atraen el agua y sus ramas de fuego,

visiones de astros,

el paraíso terrenal

decorado con pavos reales

de colores

como flores y cometas,

cuando el tigre salta

por hambre

(Gerbasi, "Retumba como un sótano del cielo", Obra poética 244)

$Y$ cuando ese espacio, cuando ese paisaje se interioriza,

resulta semejante al paraíso.

Me apresuro a desconfiar del abismo

de donde sube un rumor de trueno,

un resplandor apocalíptico de tiniebla y fuego.

Más hondo es el espacio del corazón

en cuyas comarcas se renueva el paraíso

(Gerbasi, "Retumba como un sótano del cielo", Obra poética 251)

El POEMA, FUENTE EVOCADORA: PARA RECONCILIAR AL PÁJARO CON EL HOMBRE

El poema como fuente evocadora, el compromiso de la poesía con la evocación por encima de la significación. Y Gerbasi es más radical aún: la palabra poética debe ayudarnos a fundar el Ser, en el sentido heideggeriano. Piensa, como Hölderlin, que a través de nuestra sustancia aflora el verbo que ha de develarnos el misterio de existir. Por lo tanto palabra y verbo se sustancializan en el ser que palpita en la página.

Estamos frente a un poeta obsesionado por recuperar el valor mágico, la carga mágica de las palabras. El espacio del poema es el único espacio capaz de restituir ese valor. El espacio del poema que, no olvidemos, intenta que nuestros ojos perciban "la noche poblada de hojas de plátanos como en un rincón del paraíso".

Gerbasi sabe que sólo en el poema se destruyen las máscaras del hombre y las máscaras del lenguaje.

... cuando el pensamiento

transforma mis secretos

en abismos de yedras ...

cuando siento mis pasos en la tierra, 


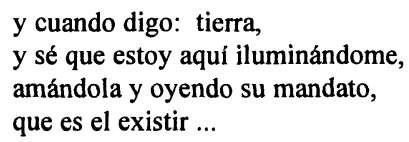

(Gerbasi, "Mi padre, el inmigrante", Obra poética 66)

Luego debemos reconocer la espacialidad primaria del lenguaje. Recordar que cuando el espacio es el que manipula la relación significado-significante, cuando el poeta insiste en evocar, en abrir su imaginario, trasciende toda dinámica de significación, e impera el mundo de la analogía: en ésto ver aquello, en el árbol que abre sus brazos hacia el cielo, se asoma Canoabo, y en Canoabo yace lo absoluto.

La página, el espacio blanco de la página, es el único espacio en el cual el poeta puede resolver la distancia entre él y el bosque.

Soy bosque susurrante en el espacio de la noche y por mis sienes pasan en las sombras las alas de la muerte ...

(Gerbasi, "Bosque doliente", Obra poética 37)

Y para darse cita con el misterio que lo seduce, no tiene sino que colocar sobre el papel al tigre y al pájaro, dejarlos que se miren hasta que uno salte sobre el otro entregándonos un puñado de arena que se convierte en luz. Porque el espacio del poema para Gerbasi, así lo aprendió de los surrealistas, es un espacio poblado de sueños, de deseos, de reconciliaciones -entre el pájaro y el hombre, por ejemplo. El poeta no tiene sino que hacer reaparecer esas figuras, resucitarlas con el aliento de la imaginación.

Junto con Mallarmé advertimos que es necesario evitar un sentido único, las certitudes. Es necesario jugar con la expresión, el blanco alrededor de las palabras, para que irradien, para que nos hagan dudar, en principio, de su sentido. En ese momento adoptan el extraño aspecto de lo "nunca visto", de lo primigenio.

\section{EL TIEMPO ESPACIO DURO: UN RESPLANDOR EN QUE ARDEN LOS GIRASOLES}

Gerbasi entendió que la literatura se dice hoy en términos de espacio, de horizonte, de paisaje, de comarca, de camino ... y, esencialmente, que a través de esas figuras el lenguaje se espacia, se habla, se escribe. Por ello enfatiza en que la escritura nos libra a la ausencia de tiempo. Nos entrega al comienzo eterno.

Sucede que el tiempo ha tomado la forma del espacio, como en el Château de Guermantes según Proust. Y, según Genette, que la palabra ha tomado la forma del silencio. Es decir, que la página en blanco es espacio latente, lugares por nacer, tiempo comprimido que invocamos para acercarnos al infinito, para sufrir el vértigo al que empuja lo revelado en un instante, la fascinación.

Ello nos permite confiar en que la poesía es lo "real absoluto". Que la poesía, hoy, es una escritura que se sabe sombra, imagen de un mundo, murmullo de lo incesante y de lo indeterminado. Por ello, entonces, escribir es permanecer en contacto con lo Abierto, 
transformar la cosa en imagen, y entender luego la imagen como alusión de lo que no tiene figura, de lo informe, de la ausencia, de ese espacio opaco y vacío que todavía no es mundo.

Ha sido borrado el tiempo. Todo es comienzo eterno. Al cruzar los versos, al herir el espacio de la página con los versos, el poeta descubre - en la duración de un instanteque el futuro no es estadía segura, que el futuro es horizonte abierto, camino sin fin y sin reposo, camino hacia adelante o hacia atrás, no lo sabemos, pero sin punto de llegada, porque gravitamos en el infinito.

Tales sentencias nos ayudan a reconocer que el tiempo sólo tiene una realidad, la del instante. "En otras palabras, el tiempo es una realidad afianzada en el instante y suspendida entre dos nadas ... Una recta blanca, toda ella de fuerza, de posibilidad, en que, de pronto, como un accidente imprevisible, fuera a inscribirse un punto negro símbolo de una opaca realidad". ${ }^{8}$

El tiempo no corre, brota. El instante bien preciado es un absoluto, según Einstein. $\mathrm{El}$ instante se nos presenta como un punto de espacio-tiempo.

En ese instante, que es lugar y presente - presente continuo, duración del poemahic y nunc, nuestra visión se transforma en visión eterna. Sentimos en él la marca, la cicatriz, de la fijeza y de la maravilla. No más tiempo encadenado, sólo tiempo que se haga lugar, que inaugure un lugar; tiempo vertical.

Ese es el tiempo que reconocemos, el tiempo vertical, suma de instantes con perspectivas metafisicas. Suma de ambivalencias, de simultaneidades, nunca de eventos sucesivos. Un tiempo que se eleva o que se hunde: que se hunde, que baja, guiado por las peores penas; que se eleva, que sube, consolidando el consuelo sin esperanza.

La obra poética de Vicente Gerbasi nos brinda mayores indicios en relación con el manejo del tiempo. Porque si bien Gerbasi es un poeta netamente espacial, el transcurrir humano también le obsesiona; quiere saber por cuánto tiempo más estaremos expulsados del seno de Dios. Le interesa el tiempo como drama existencial, como condena, como obligación de duración, como amenaza de finitud sobre la tierra.

El poeta ha dicho insistentemente que el tiempo no existe, que el tiempo lo hace uno. Ha dicho que el tiempo no lo detiene. Ha sugerido que somos un instante, "un resplandor en que arden los girasoles".

El tiempo lleva sus ojos hacia la muerte y, por ello,

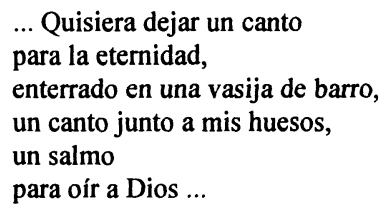

(Gerbasi, “Olivos de eternidad”, Obra poética 185).

Por temor al tiempo, Gerbasi se aferra al espacio.

${ }^{8}$ G. Bachelard, La intuición del instante (México: Fondo de Cultura Económica, 1987) 22-23. 


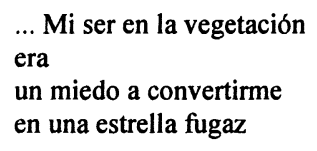

(Gerbasi, “Edades perdidas", Obra poética 285).

El poeta sabe que el tiempo labra los huesos del hombre, entonces, para salvarse, mira hacia arriba, busca el instante, el relámpago que le muestra el vuelo de las cigarras azules, las cigarras que persiguen a Dios. El tiempo que se lanza hacia arriba, hacia donde termina el bambú. Ese es el tiempo de la esperanza, del espíritu.

El tiempo vertical hacia abajo es el de la caída, caída que no nos destruye porque allí abajo hemos tratado de recuperar el paraíso.

... Mis ojos caen entre insectos voraces.
Mis ojos caen en las venas de las hojas.
Mis ojos caen en las semillas que se abren.
Caen mis ojos mortales ...
(Gerbasi, "Los espacios cálidos", Obra poética 102 ).

La última aseveración viene de labios de Rilke: el espacio imaginario, el espacio del poema, nos libera del tiempo destructor. Lo eterno se nos presenta como el circulo del tiempo cerrado sobre sí, impenetrable. Se nos presenta como un espacio duro.

EL REINO DE LA IMAGEN, EL REINO DEL INSOMNE: QUE EL ENCEGUECIMIENTO SEA VISIÓN

No queda duda de que el hombre desea huir del tiempo y del mundo de las apariencias. Entonces, como Gerbasi, se aferra a las analogías, porque "la cadena de analogías se le muestra, por instantes, como el lazo que, vinculado cada cosa con las demás, recorre el infinito y establece la indisoluble cohesión del ser". ${ }^{9}$ Tal puente entre espíritu y universo nos lo posibilitaron los románticos y adquirió su mejor dimensión a través de los modernos, con gran conciencia en el caso de Baudelaire y Rimbaud.

Hay que despertar y aprender que la imagen encarnada, esa que nos devuelve, por instantes, lo que yace a distancia, lo que invocamos, lo que queremos poseer, es eso, imagen encarnada, imagen que restituye, que reinicia el mundo. Pero la invitación de Bonnefoy es la de desconfiar de la imagen para, inmediatamente, hacerla regresar pluralizada, "respirante", respirando entre - dos- mundos.

Luego nos dirá Lezama Lima que la imagen, aunque estela, larva, es la única prueba de que existe una forma esencial, un mundo primero, una realidad. Ella es el reverso que se fija.

La imagen se le presenta a Gerbasi como la realidad del mundo irreal, no cifrable, no asible, como la emanación de lo supremo. Que el vacío que deja la imagen en su

${ }^{9}$ A. Beguin, El alma romántica y el sueño (México: Fondo de Cultura Económica, 1981) 485. 
imposibilidad de cargar consigo la cosa misma, nos coloque delante de esa cosa, nos suspenda sobre esa cosa, esa lugar. Que la analogía no desvíe la atención, sino que la centre, la sitúe; que lo dicho nos devuelva el verdadero resplandor de lo visto.

Y el último asidero de ese amante de los cafetales es Blanchot. Si la imagen, como él apunta, es aquello que nos es dado por un contacto a distancia, por ausencia, por sed, urge aprender a ver lo indeterminado, hacer que la mirada se convierta en luz, y la luz en brillo de un ojo que no ve, pero que sabe que delante de sí aletea lo incesante. Urge aprender a vivir en estado de fascinación, que el enceguecimiento sea visión. ${ }^{10}$

Porque él, gracias al grupo Viernes, a la apertura que dicho grupo propició, fue a beber en los versos de Rimbaud, Baudelaire, Rilke, Hölderlin, entre otros, y entendió que la poesía es imagen. Y, más tarde, ya en el camino, intuyó que la imagen más que alimentarse del sueño debe refugiarse, buscar camino en la mirada insomne del poeta que quiere arrancarle todos los secretos, los enigmas, a la tierra que pisa, en la que mora su espíritu: Canoabo.

Acude entonces Gerbasi para explicarnos que para anular la distancia buscó el cielo en el agua. Y buscó su voz en el aire de las islas. Y buscó su mirada en el ojo redondo del pájaro desesperado, porque tanto al mundo como a su ser, a ambos, lo reconquista a través de la imagen, de una imagen que yace entre su ojo y la realidad, como pasaje, tránsito.

\author{
Vinieron los ángeles \\ y me dijeron al oído: \\ - Mira el relámpago \\ en la nube oscura. \\ El mundo estaba abajo \\ con mis ojos absortos en un plato \\ de ramajes umbríos y de frutas, \\ y vi caer del cielo aquella lumbre \\ sobre el pan de la mesa \\ (Gerbasi, “Los colores ocultos”, Obra poética 272).
}

Vinieron los ángeles y le dijeron al oído: nuestro único padre es el morir. Somos irremediablemente huérfanos.

${ }^{10}$ M. Blanchot, L'Espace littéraire (París: Gallimard, 1985) 27. 
